Word count 8,862

Author's pre-publication proof
To appear in Organization Studies

(DOI no: 10.1177/0170840607083104)

\title{
Empirical challenges in organizational aesthetics research: towards a sensual methodology
}

\begin{abstract}
Despite growing scholarly interest in aesthetic dimensions of organizational life, there is a lack of literature expressly engaging with the methodological mechanics of 'doing aesthetics research'. This article addresses that gap. It begins with an overview of the conceptual idiosyncrasies of 'aesthetics' as a facet of human existence and maps out the challenges these pose for empirical research methodology. A review of methodological approaches adopted to date in empirical studies of organizational aesthetics is then presented. The remainder of the article draws on the author's experiences and suggests methods and techniques to address both conceptual and practical challenges encountered during the execution of an organizational aesthetics research project. The article calls for a firmer focus on the aesthetic experiences of organizational members in addition to those of researchers and concludes with some suggestions as to the future of such 'sensual methodologies'
\end{abstract}

Keywords:

Qualitative methodology; organizational aesthetics; photography; visual research; aesthetic field research methods

\author{
Author contact details: \\ Dr. Samantha Warren \\ Senior Lecturer in HRM \\ School of Management \\ University of Surrey \\ Guildford \\ Surrey GU2 7XH \\ s.warren@surrey.ac.uk
}

\section{Biography}

Samantha lives on the south coast of England with her husband and two sons and is a Senior Lecturer in the School of Management at the University of Surrey where she teaches research methods and organizational behaviour. Her current research interests include organizational aesthetics, processes of material and cultural aestheticization, visual research methods and artsbased management initiatives. She is an executive board member of SCOS, a member of the editorial collective of the journal ephemera: theory and politics in organizations and has guest edited special issues of Consumption, Markets and Culture and the Accounting, Auditing and Accountability Journal. 


\section{Introduction}

The sub-discipline of 'organizational aesthetics' urges scholars to pay attention to so-called 'nonrational' elements of organizational life in order to explore what has traditionally been hidden in mainstream organization and management studies. With roots in the study of organizational symbolism during the 1980 's, this approach is no longer particularly new, indeed there are now many excellent publications extolling the conceptual virtues of an aesthetic/ artistic take on management and organization and reporting on studies where the aesthetic approach has been fruitfully used in understanding organizational life (see, for example, Carr and Hancock 2003; Gagliardi 1996; Guillet de Monthoux 2004; Linstead and Höpfl 2000; Ramirez 1991; Strati 1999; and special issues of Consumption, Markets $\mathcal{E}$ Culture 2002, 2006; Human Relations 2002; Organization 1996). Therefore, the purpose of this paper is not to replicate the excellent conceptual advances that have already been made, but to ask in a more practical vein "how do we actually do aesthetics research?" Whilst more scholars seem to be recognising the theoretical significance and import of an aesthetic understanding of organization, suggestions about how to carry out empirical research in this regard are less forthcoming.

These aesthetic elements of organization emanate from the 'felt meanings' of organizational members - the perceptions and judgements that people make about their organizational lives based especially on their sensory encounters with the world around them. An employee's opinions about their office decor, a managerial decision to communicate a particular corporate identity in a logo and/ or corporate livery, and the 'feel' of an organization's culture are examples of aesthetic data that shed light on many aspects of organizational life. Taylor and Hansen (2005) usefully map the terrain of this flourishing scholarly field, classifying texts according to whether their content addresses 'instrumental' or 'aesthetic' issues and whether their methods of enquiry can be regarded as 'intellectual' or 'artistic'. They observe that limited attention has been paid to the fourth classification in this system - the exploration of aesthetic issues using artistic means and suggest this area offers the richest potential for advancing aesthetic understanding in organization studies. This article responds, in part, to that call and I contend that such a task requires organizational scholars to reflect on their research design and methodology first and foremost.

I hope that this article will help in the pursuit of this goal in two ways: (1) through a critical review of the methods used by other writers on organizational aesthetics; and (2) by sharing my 
Word count 8,862

Author's pre-publication proof
To appear in Organization Studies

(DOI no: 10.1177/0170840607083104)

own experiences of researching aesthetic issues in an organizational setting. Before I turn to these endeavours, I shall first lay out the idiosyncratic character of aesthetics and the outline the challenges posed by this research agenda in organizations.

\section{Challenges of an aesthetic agenda in organizational research}

The definition of aesthetics upon which this article is founded is, of course, my reading of aesthetics that I have constructed with reference to aesthetics literature (organizational and philosophical) and as a result of reflecting on my own experiences in the field. As my aim is to address the methodological issues posed by aesthetics research, not to offer another philosophical exegesis on the origins and nature of aesthetics, the summary that follows is necessarily brief not least because several excellent contributions along these lines exist already (see Gagliardi 1996; Strati 1999, 2000a and Welsch 1997 in particular). Aesthetics, as I conceptualise it, comprises three interconnected parts. These are:

1. 'The aesthetic' always implicates an external object or event (broadly defined) as a 'trigger'. Debate has raged for centuries as to whether aesthetics are entirely subjective responses or can be defined as 'significant forms' pertaining to particular objects (Warburton 2003). Here, following Linstead and Höpfl (2000), I conceptualise aesthetics as an oscillation between the two - aesthetic experiences/ judgements are subjective reactions to material things (real or imagined) but cannot be reduced to one or the other.

2. Aesthetic experiences are universal, embodied, sensory, modes of human being-in-the-world. Here I am following the original meaning of Baumgarten's doctrine of philosophical aesthetics to denote a kind of 'sensible knowledge' (Strati 1999, 2000a) that is open to all rather than reserved for the production, consumption and criticism of 'high art' (Lyas 1997). Importantly, this knowledge is acquired in the first instance by the continual stream of sense impressions that provide the backdrop to everyday life. Given their corporeal nature, aesthetic experiences are often (but not necessarily) involuntary, overwhelming and short-lived.

3. However, 'the aesthetic' is characterised by two quite conceptually distinct elements experience and judgement - the latter being an intersubjectively constructed appraisal of the former, influenced by socialization processes and 'habitus' (Bourdieu 1984) . As Welsch (1997) puts it, aesthetics has a 'double character'. 
Word count 8,862

Author's pre-publication proof
To appear in Organization Studies

(DOI no: 10.1177/0170840607083104)

But what do these observations on the nature of aesthetics mean for empirical research? I have already noted the inextricability of aesthetic experiences/ judgements from the objects that provoke them. Together with claims to pay attention to organizational objects as "symbols and pathways of organizational life" (Gagliardi 1990) the first challenge of research of this kind is that there is a clear need for the material world to be brought within the 'aesthetic frame of reference'.

Secondly, since aesthetics pertains to embodied, sensuous experience, effective aesthetic communication through language is difficult, largely because as Langer (1957) observes, aesthetic experience cannot be broken down into the basic syntactical units which language demands. At best we have to speak of our feelings metaphorically (Witkin 1974) and employ what Gagliardi (1996: 576) calls an "allusive, poetic language" to try and evoke a similar aesthetic (empathetic?) reaction in our listener, and as Strati (2000a: 13-14) tells us:

The network of the sensory perceptive faculties of both organizational actors and organization scholars produces knowledge that is not entirely verbal, nor entirely sayable. Other languages intervene, from visual to gestural, and other knowledge-creating processes, from intuitive to evocative.

Here is the second methodological challenge - how do we read (or stimulate) these alternative languages and knowledge creation processes with research participants?

Related to the issue of ineffability outlined above, a further difficulty is the momentary nature of much aesthetic experience. Very often we are dealing with something as short as a sudden pleasant rush of memory that 'tingles' through us when we hear a musical refrain or recognise a familiar smell. Thus, aesthetic experience is often fleeting, existing tantalizingly beyond our grasp. Even if researchers were constantly present in organizations, they could not be with all participants all the time, so how can these transitory experiences be 'pinned down' for later evaluation?

Finally, the intersubjectivity of aesthetic judgements presents a further challenge to aesthetics research, that of contextualisation. Although aesthetic encounters are subjectively experienced and individually embodied, the interpretation of those encounters is socially shaped. Perhaps the aesthetic experience-judgement dyad is best thought of as an oscillation incorporating cognitive and intellectual capacity as well as physical sense perception - put another way, experience informs judgements which, in turn, shade interpretation of further experience and so on ad infinitum (Martienssen 1979). How can these socio-cultural influences on aesthetic judgements be accounted for when gathering aesthetic data? 
Word count 8,862

Author's pre-publication proof
To appear in Organization Studies

(DOI no: 10.1177/0170840607083104)

I take these considerations forward to the rest of the article, beginning with a review of how organizational aesthetics researchers have dealt with their subject matter to date. I then discuss my own 'sensual methodology' developed to engage with the above challenges and conclude the article with some possibilities for the future of organizational aesthetics research.

\section{Sense, aesthetics and methodology}

Despite advances being made in other social sciences, e.g.: anthropology (Pink 2005), attention to the senses in organization studies is scant, although there have recently been some interesting developments. For example, there is a growing interest in 'the visual', evidenced by Strangleman's (2004) call to rectify the 'blind spot' in management research. An early example is Dougherty and Kunda's (1990) content analysis of photographs in the annual reports of five major corporations. Utilising images differently, Buchanan (2001) photographed the reengineering of business processes in a hospital and relatedly, Cohen et al (2006) reflect on how art photography can open up critique and debate about abjection in organizational life. Other business and management disciplines also regard the visual dimension of their subject matter as worthy of attention, for example Preston and Young (2000) who also engage in a visual critique of company annual reports, Beattie and Jones $(1992,2000)$ who analyse the effect of graphs on stakeholders' perceptions of firms' financial performance, Schroeder $(2002,2003)$ who, among other things, explores the importance of banks' architecture in transferring their services (and reputation) to the Internet and Ells (2001) who explored children's brand preferences and eating habits by asking them to photograph the contents of their school lunch-boxes and kitchen cupboards at home.

Regarding attention to the visual as occularcentric, Corbett (2003a) emphasises hearing and sound in organizational processes originating during the Middle Ages. This is a theme taken up by Linstead (2006) in his commentary on the use of musical arrangements of interview narratives about working life by the UK's BBC radio in the 1960's. Corbett (2006) also presses for attention to smell and the influence of 'olfactory symbolism', which is similarly emphasised by Martin (2002) in her study of elderly residential care homes. Likewise, Candlin's (2003) writing on museum collections calls for a greater regard for touch (or absence of it) in organizational settings, as does Rippin (2006) who ruminates over haptic representations of organizational issues in fabric quilts. Relatedly, Rehn (forthcoming) questions why taste and the tongue are also conspicuous by their absence from our disciplines - especially given the importance of food and drink in organizational ritual, celebration and everyday life. All these authors call our attention to 
Word count 8,862

Author's pre-publication proof
To appear in Organization Studies

(DOI no: 10.1177/0170840607083104)

sensation as an underutilised resource for the organizational researcher, yet only cursorily reflect on how we might enact such sensory research, leaving the reader to deduce methodological insights from 'between the lines' on their pages. It is my intention in this article to make these processes more explicit.

Notwithstanding the above, there are several studies that take empirical examples of organized aesthetics as their focus, although by and large they do not do so from within an explicitly sensory framework. These studies can be divided into those that draw on what Boyle (2003) has referred to as 'impressionistic' analyses of cultural and/ or organizational examples in the manner of a detached commentator; and those that engage with organizational members to co-construct accounts of organizational aesthetics rather than rely solely on their own aesthetic perceptive faculties (Strati 1999). Thus, I am distinguishing here between studies that privilege the researcher's voice and those that attempt to foreground the voices of organizational members. It is important to note at this juncture that I do not claim to be undertaking an exhaustive review of every empirical study in organizational aesthetics research. Although I do hope to provide a reasonable reflection of the range of studies now published in the field, my purpose is to highlight general methodological trends rather than to embark on a comprehensive review of the kind impressively undertaken by Taylor and Hansen (2005).

Studies that take the 'commentator' approach are more prevalent than those focussing on organizational members' aesthetic accounts. Jackson and Carter's (2000) study of war graves, Nissley et al.'s (2003) historical interrogation of company songs as aesthetic discourse and Dougherty and Kunda's (1990) and Cohen et al's (2006) analyses of organizational images are exemplars. All observe organizational phenomena using a range of theoretical lenses to understand their operation and impact. Likewise, Larsen and Schultz (1990), Dale and Burrell (2003) and Kersten and Gilardi (2003) all analyse the aesthetic (and anaesthetic) effects of corporate architecture in various ways, but from a similar critical distance. As Taylor and Hansen (2005) would put it, these authors apply their own intellectual analyses to aesthetic issues. Of course, methodological imperatives must also be at play in these studies given that all are empirical: they concern 'real life' examples of aesthetics-at-work. For instance, all of the above stress the importance of sensory experience in their analysis and with the exception of Nissley et al. (2003) expressly incorporate the material environment within their remit - two of the 'aesthetic challenges' I identify above. 
Word count 8,862

Author's pre-publication proof
To appear in Organization Studies

(DOI no: 10.1177/0170840607083104)

Strati $(1992,1996,1999)$ suggests that the researcher is key to aesthetic research because we sense and feel in our own experiences and are therefore able to study the aesthetics of organization. For example, he proposes that a researcher might gain a 'feel' for the aesthetics of an organizational episode by sensually experiencing it for themselves when carrying out fieldwork. He uses the term 'imaginative participant observation' (Strati 1999: 14) to describe the way we might understand organizational aesthetics by imagining ourselves in the situations described by others - even though we may not even be physically present in the organizational scenario the author is recounting. Thus we become valid sources of data in ourselves via our own aesthetic experiences; refining our capacity to empathise with others and imagining what it might be like to be them.

Whilst the researcher is undoubtedly an important source of data in their own right - indeed some would argue the only source (see for discussion Mervis and Reis-Louis 1988) - as Taylor (2002: 822) nonetheless advocates in the case of aesthetics, this approach may not be sufficient:

\footnotetext{
Because aesthetic experience is inherently subjective it makes sense as a next step to look at the aesthetic perspective of members of the organization from their own perspective. What is their aesthetic experience of organizational actions and organizational artefacts? This requires asking organizational members to take an aesthetic perspective on their own organizational environment.
}

Similarly, as Rusted (2000) has firmly reminded us, the 'commentator' method positions the researcher as 'connoisseur' assuming a privileged interpretative position in relation to others' aesthetic worlds. Furthermore, it tends to make him/ her appear as the only person possessing the refined sensibilities to adequately investigate the aesthetic matters of the study. In other words, these investigations of aesthetics in organizational life invariably invoke only the researcher's aesthetic sensibilities, rather than exploring the aesthetic responses of the people who work and live within such spheres (see also Rusted 1990: 86).

In doing this, and following Willis's (1990) notion of "grounded aesthetics" as inseparable from the cultural milieu they are generated through, Rusted urges organizational researchers to take their lead from the ethnographic methods of cultural studies and folklorists who have long recognised the importance of an immersive research strategy. Indeed, there are already some excellent examples of ethnographic studies of aesthetics. For example, Tyler and Taylor (1998) and Hancock and Tyler (2000) take a broadly ethnographic stance towards the 'exchange of aesthetics' in flight attendants work and Witz et al. (2003) continue the theme of exploring the politics and performance of 'aesthetic labour' in the hospitality sector. Letiche (2000) discusses life 
Word count 8,862

Author's pre-publication proof
To appear in Organization Studies

(DOI no: 10.1177/0170840607083104)

in a dance company, Alferoff and Knights (2003) present their case study of the 'fun and games' in call-centre agents' work, Martin (2002) recounts her evocative exploration of the management of aesthetics in a residential home for the elderly and Beadle and Könyöt (2006) take life in the circus as their focus.

The methodological issues here, then, seem to shift from 'how do we (as researchers) take an aesthetic perspective on organizational life?' to 'how do we evoke and represent others' aesthetic perspectives on organizational life?' All the above studies incorporate the perspectives of organizational members but remain strangely silent on the complexities of the methodologies employed to do this - subsuming them under the banner of 'case study' or 'ethnography'. However, other writers have sought to conceptualise possibilities for alternative, complementary research strategies. For instance, Linstead (2000: 88) considers the problem of ineffability and ponders how we might achieve an "anthropological poetics" in ethnographic research and writing, utilising the poetic genre:

“...to accept no limits to the economy of thought; to poeticize and theorize and dramatize and metaphorize as we analyze; to proceed through atopy, enigma, silence and laughter..."

Similarly, Barrett (2000: 243) notes the fleeting and processual nature of aesthetics, arguing researchers need to be open to an aesthetics of unfolding - "one that allows players to quickly notice and respond to unanticipated cues". Strati (1999: 179) refers to this as attempting to grasp the "sentiment-in-use". An unusual manifestation of this process can be seen in Case and Piñeiro (2006) who analyse the performativity of aesthetic discourses by computer programmers' online discussion forums. Finally, and in a more explicitly artistic vein, Taylor (2002) advocates the use of drawing and painting to encourage organizational members to more easily communicate their aesthetic experiences (for an anthropological viewpoint on this, see Alfonso et al. 2004).

In sum, as Küpers (2002: 28) observes, "what competent aesthetic perception and response might consist of, and whether this can meaningfully be developed, is the subject of considerable debate in its own right." And as Taylor (2002) notes, this is especially so in work organizations predisposed towards rational, purposeful endeavour where managers and employees are little used to inquisitive researchers asking them to adopt an aesthetic perspective on their work, let alone expecting them to write poetry or paint pictures. Indeed he refers to this problem as 'aesthetic muteness' in organizations and as Rippin (2006) also points out, this challenge is faced in the academe too - aesthetically sensitive methods (such as Linstead's 'anthropological poetics' 
Word count 8,862

Author's pre-publication proof
To appear in Organization Studies

(DOI no: 10.1177/0170840607083104)

or Rippin's own work with quilts) are often regarded as self-indulgent by the mainstream academic psyche, regardless of their efficacy in generating and soaking up 'aesthetic data'.

The rest of this article draws on my own experiences of conducting aesthetic research and discusses in a more practical vein how I sought to deal with the challenges thrown up by an aesthetic research agenda. Although I do not assert that these methods are any kind of definitive toolkit for aesthetics research, I do hope that my ideas go some way towards addressing academic and organizational aesthetic muteness and may help others engaging in similar projects. In the next section I outline the aims of my project in order to contextualise the methods I then discuss, providing details of the research site and including photographs taken by the participants.

\section{Towards a sensual methodology: a case study of aestheticization at Department $X$,}

The objective of the research was to explore employees' perspectives on a programme of workplace aestheticization in the web-design department (Department X) of a global, multinational IT firm (MCS) based in a rural part of the south of England. Workplace aestheticization can be defined as a (usually) managerially instigated change process designed to embellish attributes of working life in order to make them more sensually appealing to organizational members. The rationale for this is commonly and unsurprisingly articulated in terms of improved 'bottom line' business success - in the form of reduced labour turnover and/ or absenteeism, lower staff stress levels, better team spirit, motivation and morale, enhanced communication and creativity, higher productivity and so on. The premise behind this is 'the happy worker is a productive one' - a highly problematic and poorly evidenced assumption that nonetheless seems to find a high degree of cultural resonance in the developed West (Bauman 1998; Warren and Fineman 2006)

Activities that might fall under this banner are varied (see Hancock 2003), but in the present case, the aim of the aestheticization programme was to transform Department $\mathrm{X}$ into a fun, funky place to work. The changes took two broad forms: (1) cosmetic enhancement of the material office space and (2) encouragement of a culture of 'fun and play' during working hours. These two strands were related, of course, since it was hoped that the physical changes would foster a fun environment and the fun environment would lead to further enjoyment of the office space: for example, paint and lighting effects were combined to give the appearance that the office had been transformed into a 'funky' and 'futuristic' space. The office was also newly equipped with toys, games and large sculptures - the existence and use of which were intended to impart a sense of 
Word count 8,862

Author's pre-publication proof
To appear in Organization Studies

(DOI no: 10.1177/0170840607083104)

'fun' to the workplace and their use was actively encouraged during the working day. Finally, a meeting room had been incorporated and furnished along the lines of a child's soft play room with large brightly coloured foam blocks as seating, wipe-clean vinyl floors and walls and a variety of children's toys, such as giant Lego and over-size boxing glove. The photographs left and below, taken by the research participants, show two of the most striking parts of the office. INSERT FIGURES 1 AND 2 SOMEWHERE HERE

Previously, its first floor office had been a bland and characterless corporate space with poor lighting and few remarkable features (the photograph to below shows a typical example of MCS space INSERT FIGURE 3 ABOUT HERE). In addition, some of the members of Department $X$ had previously been located in a basement office with no natural light. Thus, the changes were quite substantial alterations to their working environment. Importantly, these changes were effected in the hope that staff and clients' perceptions of MCS (and their resulting behaviour and attitudes towards the company) would be enhanced, ultimately contributing to increased sales volume and revenue. Accordingly, $\mathrm{MCS}^{\prime}$ managerial rationale for the programme was twofold:

1. To create a space that would communicate the creativity of Department X's staff to clients and the public. MCS was/ is not well known for its web-design capability and to most people's minds has a reputation for 'staid respectability' rather than avant-garde innovation.

2. To provide a facilitating environment where the creativity of the staff would be enhanced. By encouraging a playful, fun environment it was hoped that staff would be more relaxed, leading to greater creativity and ultimately to more innovative web-site designs and software 'solutions' as a source of increased competitive advantage.

However, my interest in the aestheticization of Department $X$ was not managerialist - ie, aimed at evaluating whether the initiative 'worked' in the sense that the aforementioned objectives had been met. Instead, I explored how it felt to be an employee who was 'required' to play at work, executing her/ his duties in an environment where fun was explicitly encouraged (see Warren 2005a and Fineman 2006 for a discussion of these findings). Staff working at Department $X$ performed several roles that can be loosely classified as either graphic design; software programming; project management/ production; customer administration or technical support. 
Word count 8,862

Author's pre-publication proof
To appear in Organization Studies

(DOI no: 10.1177/0170840607083104)

31 participants formally took part in the study. The sample was drawn from each of the groupings above and participants were self-selecting or invited to take part on account of their role and/ or involvement in the aestheticization programme. They were each asked to take a set of photographs on a digital camera that represented to them how it felt to work at Department X. These images (some of which are included in this article) subsequently set the agenda for semistructured interviews between the participant and myself. In addition, over the ten weeks of the project, many others were involved through an ethnographic component, engaging in casual conversations and allowing me to observe their daily working practices. In sum, I employed three main methods to generate my data:

1. Semi-structured biographical interviews;

2. Respondent-led photography; and

3. 'Aesthetic ethnography'

In reality, these three elements blended together during the research and consequently I will discuss them below in a more interrelated manner than the tripartite construction above suggests. However, I do not intend to discuss the generalities of interviewing as a qualitative research method here, for this is already a well-trodden path (e.g., Kvale 1996). Instead, in what follows, I will focus on the characteristics of the interviews that were the most useful for generating aesthetic data. Furthermore, given this article's aim of discussing how we might draw out the aesthetic experiences and judgements of research participants and not researchers, I will not deal with the third element of my approach - 'aesthetic ethnography' - in any depth, since this method relied heavily on my own aesthetic relationship with the research site. However, my aesthetic experiences and judgements were also useful 'empathetic framing' of the experiences of others. Sharing my personal aesthetic reactions with the participants enabled us to discuss why we felt similarly or differently about certain features of Department $X^{\prime}$ s office space. This process generated some fascinating data, not least because the participants' judgements were often very different to mine. For them, the office was more than an aesthetic object - it was inscribed with the everyday practicalities, joys and frustrations of workaday life and symbolised in several cases recent political goings-on and departmental conflicts between management and staff. Thus, their aesthetic judgements of the space were inextricability caught up with the political economy of the department and the wider organization. Their aesthetics were "grounded" in a different way to mine - as Willis (1990) would put it - because I was able to appreciate the office space as a politically neutral 'thing-in-itself' - or even more favourably since I was grateful for being granted access to carry out my research. 


\section{Inter-views: words and pictures in aesthetics research}

Given that I have argued for the ineffability of aesthetic experience it may seem strange to be advocating the use of interviews in this context. If aesthetic experience is not reducible to language then surely it makes little sense to expect people to be able to verbalise their feelings? However, as also noted earlier, we nonetheless do try to communicate aesthetic experience in words, utilising metaphor and attempting to evoke a similar aesthetic (empathetic?) reaction in our listener by employing "allusive, poetic language" (Gagliardi 1996: 576; Witkin 1974). Thus, it was this more 'emotionally infused' facet of the interviews I particularly wished to encourage and did so by asking interviewees to tell me stories about their experiences. As Gabriel (1999) recognises, stories are rich tapestries of facts, embellishments and folklore that allow emotional undercurrents to bubble up to the surface - and so were ideal for my purposes.

The first story I asked interviewees to recount was their own biographical or 'life-history' narrative (Musson 2004). Beginning the process with a familiar topic was intended partly as a rapport-building exercise, but also as a way of getting interviewees used to the story-telling mode. As well as enabling the allusive language outlined above, these stories sparked fascinating dialogue on how the interviewees' 'habitus' (Bourdieu 1984) influenced their perception of working life. In concentrating on this 'enabling context' I was able to ask the respondent to reflect on possible linkages between, for example, childhood past-times and adult aesthetic preferences which further enriched the data by effectively bringing the past into the equation and helping to socially contextualise their aesthetic judgements. For example, when questioned why she found working in a countryside location so appealing, one interviewee recounted that happy memories of a rural childhood were undoubtedly a factor in her assessment of a 'nice place to work'. Conversely, another participant who had enjoyed playing with Lego blocks as a child shunned their appearance in her workplace as an adult, as she explains here:

\footnotetext{
"We don't use Lego, I think that's a nonsense - its what I played with when I was a kid! We might muck about with it every now and again but that has nothing to do with work."

(Deb, Designer)
}

The rest of the interviews continued to generate rich narrative data. The social dimension of aesthetic judgements was once again recognisable in the ways these stories fitted together or diverged from one another and in several cases this helped me to gain some sense of the context in which aesthetic judgements were being made; ie: the everyday political nature of the 
Word count 8,862

Author's pre-publication proof
To appear in Organization Studies

(DOI no: 10.1177/0170840607083104)

Department. A particularly striking example of this was a story about an incident where some of the staff of Department $X$ had become so incensed by the presence of what they considered to be ugly, kitsch sculptures (shaped like giant 'Russian Dolls', see left INSERT FIGURE 4 SOMEWHERE NEAR HERE) that they physically 'attacked' them by punching one of the Dolls in the face. These Dolls had been imposed by management and at great expense (so it was rumoured). This story was told to me in many variants - sometimes with humour, other times with embarrassment and even anger, but importantly all opened up a space to understand why these objects were so aesthetically despised through their colourful retellings. As Coffey (1999) notes, the emotional elements to fieldwork are often overlooked or downplayed (see also Kleinmann and Copp 1993), however in this research it was exactly those dimensions that added to the aesthetic richness of the data, by encouraging participants, among other things, to tell stories, laugh, joke, be angry and describe their experiences and feelings in 'flowery' allusive language - and so counter the difficulties of linguistically conveying aesthetic feeling.

The image reproduced above was taken by one of the participants in the study and it is to the important role of photography in the interview process that I now turn. To reiterate, in advance of the interviews, I issued a digital camera to participants with the instruction that they should take photographs that simply 'showed me how it felt to work at Department $X$ '. These images were then jointly viewed and discussed. This technique is known by various names depending on the discipline concerned, but usually comes under the label of 'photo-elicitation' (Collier and Collier 1986); 'auto-driving' (Heisley and Levy cited in Hurworth 2003); a model of visual 'collaboration' (Harper 1998); 'photo-interviewing' (Schwartz 1994) or 'photo-novella' (Wang \& Burris 1994, 1997). All variants differ slightly - see Hurworth 2003 for a concise overview and Parker 2006 for a fuller one. However, the main premise that unites them is that a respondent and researcher discuss an image or photograph in some way to generate data.

With particular regard to aesthetics, the photographs generated appropriate data in a number of ways: (1) by acting as a window on participants' aesthetic worlds; (2) by evoking and 'recreating' aesthetic experiences during the interviews; and (3) operating as sites through which to explore the socially constructed nature of the participants' aesthetic judgements.

The first benefit, as alluded to above, was that participants were free to photograph whatever they chose - immediately highlighting what was aesthetically important for them in their working environment. Consciously or not, the visual culture of the photographer conditions what 
Word count 8,862

Author's pre-publication proof
To appear in Organization Studies

(DOI no: 10.1177/0170840607083104)

is included in (or left outside) the photograph's frame, the choice of subject, its position in the overall composition, the angle and orientation of the camera, and so on. Thus, a photograph probably tells us more about the culture of the photographer than the culture of what is photographed (see for example, Scott 1999 and Pink 2001). When I first arrived, I had begun to photograph the office myself, but became increasingly aware that these images portrayed my aesthetic preferences - not those of my participants - so I decided to ask them to take the pictures. Since it was the aesthetic experiences and judgements of the participants that I was particularly interested in, this trait of photography was extremely useful.

However, at this point it became clear that my 'purely' inductive stance was going to prove problematic. In a case of Taylor's (2002) 'aesthetic muteness', the participants wanted me to tell them what they should take pictures of! Treading a fine line between leading them to particular objects and helping them interpret the research brief, I directed them to photograph things they liked, disliked, had particular meaning for them, or even that they considered bland, boring or meaningless - hoping to generate aesthetic data by asking people to make judgements of taste about elements of their work environment. Strati (1999: 140) describes a similar strategy when he recounts asking research participants whether they considered their work to be 'beautiful'.

The second notable characteristic of photography for aesthetics research was that during the interviews, we talked about the places, objects and people in the images as if they were actually there with us. The iconographic nature of photography means that we act as if we are relating to the thing depicted itself when we view the photograph ourselves and show it to others - no matter how posed, partial, or otherwise constructed we might also know the image to be (Harper 1998). Thus the photographs almost literally brought the material environment 'into' the interview room and given my earlier argument that aesthetic experiences necessarily implicate an object, this is a helpful facet of the approach.

In addition to serving as points of reference for verbal descriptions (talking about the content of the image) photographs also arouse aesthetic experiences in their own right. Indeed, the power of photography as an art genre is testament to this fact (Strati 2000b). Although these photographs were visible depictions of objects from Department $X$ and indeed, outside the office, what they 'conjured up' in the interviews was a much more sensory experience. Pink (2001) notes this as the difference between what is visible and what is visualised - the latter being intrinsically bound up with richly infused remembrances and memories of 'being there' and apprehending the artefact in the photograph. This also has the advantage of virtually 'recreating' aesthetic experiences in 
Word count 8,862

Author's pre-publication proof
To appear in Organization Studies

(DOI no: 10.1177/0170840607083104)

the interview setting, - much as one gets 'transported back' while looking at one's own happy holiday snapshots - and this goes at least some way towards addressing the issue of the transience of aesthetic experience I noted above. To give an example from my study, one participant photographed the branches of a tree (INSERT FIGURE 5 ABOUT HERE) to explain to me how, in summer, she valued being able to lie on the grass outside the office, looking up at the trees and sky, 'smelling the air' and feeling the grass on her skin. In this example what seemed of most import was not what was actually visible but what the image allowed its photographer to visualise which included recollections of sensory experiences other than sight.

What the photograph engenders beyond itself is significant in another way too on account of the fact that discussing photographs is a social act. This is beneficial to aesthetics research as it allows the socially constructed nature of aesthetic judgements to be explored. As I noted at the beginning of this section, my 'aesthetic ethnographic' observations were useful in empathising with and reflecting on differences between mine and others' interpretations and this led to interesting conversational detours. Furthermore, the way the photographs were interpreted during the interviews was different from the photographer's original motivation for taking them and the viewer's subsequent solo understanding of them. Belova (2006: 47) refers to this as the 'event of seeing' where "...meaning is created in movement and dialogue between image, author, viewer and circumstance of perception and/ or discourse": instigating a 'can opener effect' whereby the conversations that are triggered by the image lead to all sorts of interesting and often unexpected data (Walker and Weidel 1985). The photograph and excerpt from its accompanying interview transcript below illustrate this process.

\section{INSERT FIGURE 6 BESIDE QUOTE}

\section{Me: What's this a picture of?!}

Simon: It's a plasma screen image that I just liked [artwork displayed on a large computer screen in the office foyer] - it's actually done by the technical continuity director - one of my management level buddies and he really enjoys taking photographs and whether or not you think he's got that talent ... he enjoys doing it and that's his free space for him to air -and I think its just as important to realise that we are all creative.

\section{Me: Is everyone able to put stuff on the screens?}

Simon: They are. Now that there's a lot of interest and there's a lot of people doing it, it'll be vetted to a degree - against criteria, sensitivities etc um, but yeah they're free to...

\section{Me: Even support staff [clerical administrators]?}

Simon: Yeah - I guess the push [to display artwork] has been for the... creative people - all the do-ers on the projects - the designers, the developers and the producers I don't think any of the infrastructure staff [have]... Perhaps they need to be told that a bit more clearer, but yeah - it's very much a free space. 
During questioning, Simon reveals that he took the photograph because he believes creativity is universal - something which is certainly impossible to guess from looking at the image alone. However, my further probe as to whether everyone is free to display artwork on these publicly visible screens reveals that it is not such a 'free' space as Simon claims since the images are 'vetted' for appropriateness. When I ask if this 'freedom' extends to all the staff, we sense that Simon actually considers the 'do-ers' on the projects to be the only ones who should be labelled 'creative' and he tells us that they have been 'pushed' to contribute - contradicting his final claim that the screens represent a 'free space' and earlier rationale for taking the photograph as representing the universal nature of creativity. Importantly for my purposes here, that rationale was first and foremost an aesthetic one: Simon took the photograph because he liked the image.

The above notwithstanding, what remains unequivocal from these data and the preceding discussion is the importance of language - more precisely, discussion during the interviews - in contextualising the photographs and generating data through them. The relationship between language and image is a long-standing and complex debate beyond the scope of this particular article (see Mitchell 1994; Scott 1999; Warren 2002, 2005b), but it is important to stress that the efficacy of these 'photo-interviews' in aesthetics research springs from the combination of the photograph and discussion, and not from either one or the other.

To sum up this section, my sensual methodology attempted to draw the aesthetic experiences of my research participants to the fore in a number of ways. Framed by my own aesthetic relationship with Department X, I developed qualitative interviews into aesthetically attuned arenas; encouraging the telling of stories about participants' 'aesthetic biographies' and the objects, places and people that they deemed significant enough to photograph in their working environment. These photographs added a 'virtual' tangible material dimension to the discussions about them, and evoked sensory recollections that extended beyond what they visibly represented, allowing a kind of 're-feeling' that helped to capture some sense of what it might have felt like to be physically apprehending the scene within its frame. Finally, viewing the photographs collaboratively, facilitated reflection on the socially constructed nature of aesthetic judgements through conversations about differences in our aesthetic interpretations.

\section{Conclusion}


Word count 8,862

Author's pre-publication proof
To appear in Organization Studies

(DOI no: 10.1177/0170840607083104)

My aim in this article has been to explicitly draw methodological issues to the forefront of discussions of organizational aesthetics and I hope to have done this in three ways.

(1) I began by bringing together and restating conceptual literature that reminds us what makes aesthetic research especially problematic. This was expressed as a series of challenges for organizational researchers, carried forward throughout the article as various methodological positions were discussed.

(2) I then conducted a review of methodological approaches taken in a range of empirical studies of aesthetics in organizational settings, noting that studies taking a researcher-ascommentator or 'connoisseur' perspective (Rusted 2000) were more prevalent than those addressing the experiences of organizational members themselves. Those that do take such a focus tend to rely heavily on 'traditional' ethnographic strategies - with alternative possibilities (such as haptic representation (Rippin 2006), olfactory symbolism (Corbett 2006) and anthropological poetics (Linstead 2000) seeming still to be at a highly speculative and experimental stage.

(3) Finally, I put forward reflections on my own experiences of carrying out a case study in an aestheticized organizational environment in the spirit of advancing these 'sensory possibilities' in organization studies in order to assist others wanting to overcome 'aesthetic muteness' among organizational members and in the scholarly community. Whilst I would not go so far as to claim that the approach detailed above surmounts the challenges of an aesthetic research agenda, I would suggest that it does embrace these difficulties.

Of course, this brings with it a whole host of related problems regarding the dissemination of aesthetic research accounts - matters I do not have space to deal with here (see Warren 2002, Gagliardi 1996) but which others are making advances in. Pink's (2001, 2006) work with multimedia presentations opens up new possibilities for expressing organizational life in a nonlinear fashion, blending image, sound and narrative in a way that resembles Strati's (2005) conceptualisation of organization as 'aesth-hypertext'. Although multimedia and the Internet are still two dimensional, they can bring together sight, sound and 3-D modelling to bring research accounts alive in new and exciting ways. If we also consider the almost synaesthesic properties of powerful, high resolution digitised images, we can almost imagine smell and touch to be communicable using these media. In a lecture on visual research methods, I display a large, full colour photograph of a rotting fish and watch as students physically recoil from the projector screen in disgust at the smell they can almost sense in their imaginations. Aesthetics, through digital media and Internet technologies, are thus potentially more accessible to our scholarly 
Word count 8,862

Author's pre-publication proof
To appear in Organization Studies

(DOI no: 10.1177/0170840607083104)

communities and students than the print-based outlets we so dearly cling to. Indeed, some online journals are now beginning to realise these possibilities - although not explicitly related to aesthetics, see for example, the recent issue $5(X)$ of the online journal ephemera: theory and politics in organizations that combined image, text, movie and sound to convey the proceedings of an academic conference held on the Trans-Siberian express train in 2005.

To conclude this article then, I support Taylor and Hansen's (2005) call for more research that employs artistic/ aesthetic methods to explore aesthetic issues in organizational life. Thus I hope this conclusion may in actuality be only the beginning of a rich and sensual branch of aesthetics research. Gagliardi (1990: 31) sums this up with characteristic linguistic flair:

"...what we have 'felt' that the natives 'feel' can only be given in a way that enables our audience to 'feel' and it demands that we use our creative imaginations. The aesthetic experience should be transmitted in ways consonant with its nature"

\section{References}

Alferoff, Catrina and David Knights (2003) ‘We're all partying here: targets and games, or targets as games in call centre management', in A. Carr \& P. Hancock (eds.) Art and aesthetics at work, London: Palgrave Macmillan, 70 - 92

Alfonso, Ana-Isobel, Laslo Kurti and Sarah Pink (2004) Working images: visual research and representation in ethnography, London: Routledge

Warren, Samantha (2002) 'Show me how it feels to work here: The role of photography in researching organizational aesthetics' ephemera: theory and politics in organization, 2/ 3: 224 - 245 available at www.ephemeraweb.org

Warren, Samantha (2005a) Consuming work? An exploration of organizational aestheticization Unpublished PhD thesis, University of Portsmouth, UK

Warren, Samantha (2005b) 'Photography and voice in critical, qualitative, management research' Accounting, Auditing and Accountability Journal, 18/ 6: 861 - 882

Warren, Samantha and Stephen Fineman (2006) 'Don't get me wrong, it's fun here but...': ambivalence and paradox in a 'fun' work environment' in Carl Rhodes and Bob Westwood (eds.) Humour and organization, London: Routledge, forthcoming

Barrett, Frank (2000) 'Cultivating an aesthetic of unfolding: Jazz improvisation as a selforganizing system' in Stephen Linstead and Heather Höpfl (editors) The aesthetics of organizing, London: Sage, 228 - 245

Bauman, Zygmunt (1998) Work, consumerism and the new poor, London: Sage 
Word count 8,862

Author's pre-publication proof
To appear in Organization Studies

(DOI no: 10.1177/0170840607083104)

Beadle, Ron and David Könyöt (2006) 'The man in the red coat - management in the circus' Culture and Organization, 12/2: 127 - 138

Beattie, Vivian and Michael Jones (1992) 'The use and abuse of graphs in annual reports: theoretical framework and empirical study', Accounting and Business Research, 22/ 88: 291 - 303

Beattie, Vivian and Michael Jones (2000) 'Impression management: the case of inter-country financial graphs' Journal of International Accounting, Auditing and Taxation 9/ 2: 159 - 183

Belova, Olga (2006) 'The event of seeing: A phenomenological perspective on visual sensemaking' Culture and Organization, 12/2: 93 - 107

Bourdieu, Pierre (1984) Distinction: a social critique of the judgement of taste, London: Routledge

Boyle, Mary-Ellen (2003) 'Reconciling aesthetics and justice in organization studies' in A. Carr and P. Hancock, Art and aesthetics at work, London: Palgrave Macmillan, 51 - 64

Buchanan, David (2001) 'The role of photography in organization research: a reengineering case illustration' Journal of Management Inquiry, 10/2: 151 - 164

Candlin, Fiona (2003) 'Can matter think? Touch and knowing in museum collections' Paper presented to the $22^{\text {nd }}$ meeting of the Standing Conference on Organizational Symbolism, Halifax, Canada, July 2003

Carr, Philip and Adrian Hancock (2003) Art and aesthetics at work, London: Palgrave

Case, Peter and Erik Piñeiro (2006) 'Aesthetics, performativity and resistance in the narratives of a computer programming community' Human Relations, 59/6: 753 - 782

Coffey, Amanda (1999) The ethnographic self, London: Sage

Cohen, Laurie \& Melissa Tyler (2004) 'The office (27 November 2003 - 18 January 2004), The photographers' gallery, London: a review' Work, Employment and Society 18/ 3: 621 - 629

Collier, John \& Margaret Collier (1986) Visual anthropology: photography as a research method, Albuquerque: University of New Mexico Press

Consumption, Markets and Culture (2002) Special issue, 'Building bridges to art', 5/ 1

Consumption, Markets and Culture (2006) Special issue, 'The art of oppression', 9 / 2

Corbett, Martin (2003a) 'Sound organization: A brief history of psychosonic management' Ephemera: Theory \& Politics in Organization, 3/ 4: 265 - 276 available at www.ephemeraweb.org

Corbett, Martin (2006) 'Scents of identity: organization studies and the cultural conundrum of the nose' Culture and Organization. 12/3: 221 - 232

Dale, Karen and Gibson Burrell (2003) 'An-aesthetics and architecture' in A. Carr \& P. Hancock (eds.) Art and aesthetics at work, London: Palgrave, 155 - 173

Dougherty, Deborah and Gideon Kunda (1990) ‘Photograph analysis: a method to capture organizational belief systems' in Pasquale Gagliardi (ed.) Symbols and Artefacts: Views of the corporate landscape, Berlin: Walter de Gruyter, 185 - 206 
Word count 8,862

Author's pre-publication proof
To appear in Organization Studies

(DOI no: 10.1177/0170840607083104)

Ells, Harvey (2001) 'Talking pictures in working school lunches: investigating food choice with children and adolescents.' British Food Journal, 103/6: 374 - 382

Gabriel, Yiannis (2000) Storytelling in organizations: facts, fictions and fantasies, Oxford: Oxford University Press

Gagliardi, Pasquale (1990) Symbols and artifacts: views of the corporate landscape Berlin, New York: de Gruyter

Gagliardi, Pasquale (1996) 'Exploring the aesthetic side of organizational life' in Stuart Clegg, Cynthia Hardy and Walter Nord, eds. Handbook of organizational studies, Sage: London, 565 - 580

Guillet de Monthoux, Pierre (2004) The art firm: aesthetic management and metaphysical marketing, California: Stanford University Press

Hancock, Philip and Melissa Tyler (2000) 'The look of love: gender and the organization of aesthetics' in J. Hassard, R. Holliday \& H. Willmott (eds.) Body and Organization, London: Sage, $108-129$

Harper, Douglas (1998) 'An argument for visual sociology' in Jon Prosser (ed.) Image-based research: a sourcebook for qualitative researchers, London: Falmer Press $24-41$

Human Relations (2002) Special issue 'Organizing aesthetics' 55/ 7

Hurworth, Rosalind (2003) ‘Photo-interviewing for research’ Social Research Update, 40

Jackson, Norman \& Pippa Carter (2000) 'An-aesthetics' in Stephen Linstead and Heather Höpfl (eds.) The aesthetics of organization, London: Sage, 180 - 196

Kersten, Astrid and Ronald Gilardi (2003) 'The barren landscape: reading US corporate architecture' in in A. Carr \& P. Hancock (eds.) Art and aesthetics at work, London: Palgrave Macmillan, 70 - 92

Kleinman, Sheryl \& Martha Copp (1993) Emotions and fieldwork, Qualitative Methods Series 28, Sage University Papers, London: Sage, 138 - 154

Küpers, Wendelin (2002) 'Phenomenology of aesthetic organizing - ways towards aesthetically responsive organizations' Consumption, Markets and Culture, 5/1: 21 - 46

Kvale, Steinar (1996) InterViews London: Sage

Langer, Suzanne (1957) Philosophy in a new key, Milton Keynes: Open University Press

Larsen, Janne and Majken Schultz (1990) 'Artifacts in a bureaucratic monastery' in P. Gagliardi (ed.) Symbols and artefacts: views of the corporate landscape, Berlin: Walter de Gruyter, 281 - 302

Letiche, Hugo (2000) 'Observer versus audience' in S. Linstead and H. Höpfl (eds.) The aesthetics of organizing, London: Sage, 154 - 179

Linstead, Stephen (2000) 'Ashes and madness: The play of negativity and the poetics of organization' in S. Linstead and H. Höpfl (eds.) The aesthetics of organizing, London: Sage, 61 - 92 
Word count 8,862

Author's pre-publication proof
To appear in Organization Studies

(DOI no: 10.1177/0170840607083104)

Linstead, Stephen (2006) 'Exploring culture with the Radio Ballads: using aesthetics to facilitate change' Management Decision, 44/4: 474 - 485

Linstead, Stephen and Heather Höpfl (2000) The aesthetics of organizing, London: Sage

Lyas, Colin (1997) Aesthetics, London: UCL Press

Martin, Patricia (2002) 'Sensation, bodies, and the 'spirit of the place': aesthetics in residential organizations for the elderly' Human Relations, 55/ 7: 861 - 885

Martienssen, Heather (1979) 'A note on formalism' British Journal of Aesthetics, 19/ 1: 144 - 146

Mervis, P. and Meryl Reis-Louis (1988) 'Self-full research: working through the self as instrument in organizational research', in D. Berg and K. Smith (editors), The self in social inquiry: researching methods, London: Sage, 229 - 246

Musson, Gill (2004) 'Life histories' in Catherine Cassell \& Gillian Symon (editors) Essential guide to qualitative methods in organizational research London: Sage, $34-44$

Nissley, Nick, Steve Taylor, and Orville Butler (2003) 'The power of organizational song: an organizational discourse and aesthetic expression of organizational culture' in A. Carr and P. Hancock (editors) Art and aesthetics at work, London: Palgrave Macmillan, 93 - 114

Organization (1996) Special issue on 'Essays on aesthetics and organization', 3/ 2

Parker, Lee (2006) 'Photo-elicitation: an ethno-historical accounting and management research prospect' paper presented to the Interdisciplinary Perspectives on Accounting conference, Cardiff, Wales, July.

Pink, Sarah (2001) Doing visual ethnography, London: Sage

Pink, Sarah (2005) The future of visual anthropology: engaging the senses, London: Routledge

Pink, Sarah (2006) personal webpage at

http:// www.lboro.ac.uk/departments/ss/depstaff/staff/bio/pink.htm last accessed 25/10/06

Preston, Alistair \& Joni Young (2000) 'Constructing the global corporation and corporate constructions of the global: a picture essay' Accounting, Organizations and Society 25: 427 - 449

Ramirez, Rafael (1991) The beauty of social organization, Munich: Accedo

Rehn, Alf (forthcoming) 'The tongue in economy' Spices, the value of taste and the tongue in economy, Abo: Dvalin Books

Rippin, Ann (2006) 'Refusing the therapeutic: Marion Milner and me' Culture and Organization, 12/1: $25-36$

Rusted, Brian (1990) 'Housing modifications as organizational communication' in Pasquale Gagliardi (ed.) Symbols and artefacts: views of the corporate landscape, Berlin: Walter de Gruyter, 85 106

Rusted, Brian (2000) 'Cutting a show: grounded aesthetics and entertainment' in in S. Linstead and H. Höpfl (eds.) The aesthetics of organizing, London: Sage, 111 - 129 
Word count 8,862

Author's pre-publication proof
To appear in Organization Studies

(DOI no: 10.1177/0170840607083104)

Schroeder, Jonathan (2002) Visual consumption, London: Routledge

Schroeder, Jonathan (2003) 'Building brands: architectural expression in the electronic age' in L. Scott \& R. Batra (editors) Persuasive imagery: a consumer response perspective: New Jersey: Lawrence Erlbaum, 349 - 382

Schwartz, Dona (1994), "Visual ethnography: using photographs in qualitative research" Qualitative Sociology, 12/ 2: 119-154

Scott, Clive. (1999) The spoken image: photography \& language, London: Reaktion Books

Strati, Antonio (1992) 'Aesthetic understanding of organizational life' Academy of Management Review, 17/ 3: $568-581$

Strati, Antonio (1996) 'Organizations viewed through the lens of aesthetics' Organization 3/ 2: 209 $-218$

Strati, Antonio (1999) Organization and aesthetics, London: Sage

Strati, Antonio (2000a) 'The aesthetic approach in organization studies' in Stephen Linstead and Heather Höpfl (editors) The aesthetics of organizing, London: Sage

Strati, Antonio (2000b) "Putting people in the picture: art and aesthetics in understanding organizational life", Organization Studies, 21/ 0: 53 - 69

Strati, Antonio (2005) ‘Designing organizational life as 'aesth-hypertext': insights into business practice' Organization, 12/6: 919 - 923

Strangleman, Tim (2004) 'Ways of (not) seeing: the visual as a blind spot in WES?' Theory, Culture and Society, 18/ 1: $179-192$

Taylor, Steve (2002) 'Overcoming aesthetic muteness: researching organizational members aesthetic experience' Human Relations, 55/ 7: 821 - 840

Taylor, Steve and Hans Hansen (2005) 'Finding form: looking at the field of organizational aesthetics' Journal of Management Studies, 42/6: 1211 - 1230

Tyler, Melissa and Steve Taylor (1998) 'The exchange of aesthetics: women's work and 'the gift' Gender, Work and Organization, 5/3: 165 - 171

Walker, Rob \& Janine Weidel (1985) 'Using photographs in a discipline of words' in Robert Burgess (ed.) Field methods in the study of education, London: Falmer Press, 191 - 216

Wang, Caroline \& Mary-Ann Burris (1994) 'Empowerment through photo novella: portraits of participation' Health Education Quarterly, 21/ 2: 171 - 186

Wang, Caroline \& Mary-Ann Burris (1997) 'Photovoice; concept, methodology and use for participatory needs assessment' Health and Behaviour, 24/ 3: $369-387$

Warburton, Nigel (2003) The art question, London: Routledge

Welsch, Wolfgang (1997) Undoing aesthetics, London: Sage 
Word count 8,862

Author's pre-publication proof
To appear in Organization Studies

(DOI no: 10.1177/0170840607083104)

Willis, Paul (1990) Common culture, CO: Westview Press

Willis, Paul (2000) The ethnographic imagination, London: Polity Press

Witkin, Robert (1974) The intelligence of feeling , London: Heinemann

Witz, Anne, Chris Warhurst and Dennis Nickson (2003) 'The labour of aesthetics and the aesthetics of organization' Organization, 10/1: 33 - 54 